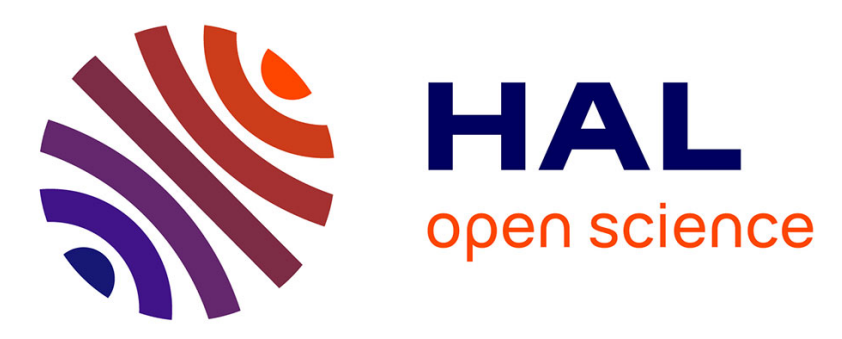

\title{
Influence of the emollient on emulsions containing lamellar liquid crystals: from molecular organization towards applicative properties
}

Daria Terescenco, G. Savary, C. Picard, F. Clemenceau, E. Merat, Michel Grisel

\section{To cite this version:}

Daria Terescenco, G. Savary, C. Picard, F. Clemenceau, E. Merat, et al.. Influence of the emollient on emulsions containing lamellar liquid crystals: from molecular organization towards applicative properties. International Journal of Cosmetic Science, 2018, 40 (6), pp.565-574. 10.1111/ics.12498 . hal-02337517

\section{HAL Id: hal-02337517 https://hal.science/hal-02337517}

Submitted on 29 Oct 2019

HAL is a multi-disciplinary open access archive for the deposit and dissemination of scientific research documents, whether they are published or not. The documents may come from teaching and research institutions in France or abroad, or from public or private research centers.
L'archive ouverte pluridisciplinaire HAL, est destinée au dépôt et à la diffusion de documents scientifiques de niveau recherche, publiés ou non, émanant des établissements d'enseignement et de recherche français ou étrangers, des laboratoires publics ou privés. 


\title{
Influence of the emollient on emulsions containing lamellar liquid crystals: from molecular organization towards applicative properties
}

Daria Terescenco $^{1} *$, Geraldine Savary ${ }^{1}$, Celine Picard ${ }^{1}$, Florence Clemenceau ${ }^{2}$, Emmanuelle Merat $^{2}$, Michel Grisel $^{1} *$

${ }^{1}$ Normandie Univ, UNIHAVRE, FR 3038 CNRS, URCOM, 76600 Le Havre, France

${ }^{2}$ Direction Innovation - UID Excipients SEPPIC, 127 Chemin de la Poudrerie, 81105 Castres Cedex, France

daria.terescenco@univ-lehavre.fr

celine.picard@univ-lehavre.fr

michel.grisel@univ-lehavre.fr

geraldine.savary@univ-lehavre.fr

florence.clemenceau@airliquide.com

* Corresponding author.

TEL: +33232743911

\section{Keywords}

Emulsion / Formulation / stability / liquid crystals/ $\alpha$-gel / emollients / molecular organization / applicative properties

\author{
Abbreviations \\ APG: alkyl polyglucoside \\ CCT: caprylic capric triglycerides \\ CTFA: Cosmetic, Toiletry and Fragrance Association \\ DTG: thermogravimetric derivative \\ IHD: isohexadecane \\ PMMA: poly(methyl methacrylate) \\ SD: standard deviation \\ SLS: static light scattering \\ TGA: thermogravimetric analysis \\ WAXD: wide-angle $X$-ray diffraction
}




\section{Abstract}

OBJECTIVE:

The sensory perception of cosmetic emulsions is complex as it is governed by an important number of parameters like the choice of raw materials, their interactions, the structural organisation of the system, etc.

The aim of the present work was to go further in the interpretation of the emollient-surfactant interactions, towards the emulsions applicative properties. For this purpose, two systems containing liquid crystals of the lamellar type were formulated, differing only in the selected emollient.

\section{METHODS:}

First, the liquid crystals types were checked using different tools like the optical microscopy under the bright and polarized light, the wide-angle $X$ rays diffraction and, finally, thermogravimetric analysis.

Next, two sensory attributes, namely compression force and difficulty of spreading, were evaluated by a sensory panel. In addition to that, complementary instrumental characterizations (flow tests, textural analysis and contact angle measurements) were performed in order to understand how the panel could discriminate the products.

\section{RESULTS:}

The results showed that isohexadecane emollient induces the $\alpha$-gel structures, while caprylic capric triglycerides favour the formation of the lamellar liquid crystals near to $\alpha$-gel.

For the compression force, the results point out that there is no direct interaction between the oil phase and the skin. For this attribute, depending on its chemical structure, emollient impacts the human perception only by changing the lamellar phase type. Concerning the difficulty of spreading, both the emulsion structure and the emollient properties should be considered. Immediate perception is impacted by the emulsions destruction, making the droplet roll one on each other. Then, once the droplets monolayer is disrupted, the emollient comes into direct contact with the skin. In this case, the perception is governed by the direct affinity of the emollient with the skin, nonpolar emollients being easier to spread if compared to polar ones.

\section{CONCLUSION:}

The sensory perception is guided not only by the choice of the raw materials but also by their interactions. It was shown that the chemical structure of the emollients affected the molecular organization of liquid crystals present in the emulsion and, consequently, directly or indirectly its sensory perception. 


\section{Introduction}

Most of the skin care formulations are of emulsion type. An emulsion is a system in which droplets of a liquid are dispersed in a second liquid, the two liquids being partially or totally immiscible (water/oil) [1]. One of the most efficient ways to stabilize an emulsion is the use of the surfactant, by means of the interfacial tension decrease. Moreover, depending on its structure, the surfactant may organize itself in liquid crystals of either hexagonal, lamellar or cubic type [2]. These structures can provide a better stability to the system and are able to change its microscopic and macroscopic properties. But at the same time, the liquid crystals organization can be affected by other ingredients present in the formulation.

Our previous study [3], based on the surfactant of the alkyl polyglucoside (APG) type, demonstrated its ability to form lamellar liquid crystals. Several types of lamellar phases, $L_{\alpha}, L_{\beta}, L_{\gamma}, L_{\beta^{\prime}}, L_{\delta}, L_{s}$, and $P_{\beta^{\prime}}$ were observed in lyotropic phase diagrams [4] but two main lamellar organizations are prevailing: lamellar liquid crystals $\left(\mathrm{L}_{\alpha}\right)$ and $\alpha$-gel $\left(\mathrm{L}_{\beta}\right)$. The alkyl polyglucoside surfactant, Cetearyl alcohol $\left(\mathrm{C}_{16}-\mathrm{C}_{18} \mathrm{OH}\right)$ / Cetearyl glucoside $\left(\mathrm{C}_{16}-\mathrm{C}_{18} \mathrm{APG}\right)$, forms exclusively $\alpha$-gel in binary systems (composed only of water and surfactant). In this case, the hydrocarbon chains remain stiff, perpendicular to the plane of the lamellae, with axes organized as a two-dimensional hexagonal lattice [5]. Considering together the theory and our previous results, the next step of our work consisted in the investigation of the behaviour of the lamellar organization through the addition of the emollient to the binary system.

Emollients are defined by CTFA dictionary as "Cosmetic ingredients which help to maintain the soft, smooth, and pliable appearance of the skin. Emollients function by their ability to remain on the skin surface or in the stratum corneum to act as a lubricant, to reduce flaking, and to improve the appearance of the skin" [6]. Due to their properties, emollients are part of the emulsions oil phase. Different studies [7-10] demonstrated that the chemical structure and the polarity of emollients affect emulsions organisation, sensory properties as well as interactions with the skin. As a function of their chemical structure, they can be either "nonpolar" (e.g. paraffin and isoparaffin) or "polar" substances (e.g. esters and triglycerides), although this polarity parameter is seldom determined or given [11].

In previous work, seven studied emollients were divided into two groups depending on the presence of heteroatom in their chemical structure. Heteroatom-free oils were more likely to keep the $\alpha$-gel organization in the system. But once a heteroatomcontaining emollient is introduced to the matrix, a complementary, lamellar liquid phase $\left(L_{\alpha}\right)$ is formed. In the $L_{\alpha}$ phase, the hydrocarbon chains of the surfactant are in a liquid-like state [5]. As a consequence, we could establish that both the microscopic and macroscopic properties of the emulsions are strongly related by the emollient structure.

The objective of the present study is to go further in the exploration of the lamellar phases properties formed in cosmetic emulsions through the applicative characterization. For this purpose, two systems were considered. The first one was prepared using isohexadecane as emollient, to assure the $\alpha$-gel formation. The second one was formulated with caprylic capric triglycerides, a polar emollient with a heteroatomic structure. In addition to the $\alpha$-gel, this second emulsion also contained lamellar liquid crystals. Two sensory attributes were selected to describe the applicative properties of these emulsions, namely: compression force and difficulty of spreading. These attributes were evaluated using both sensory and instrumental approach. Then, interdependency between the emulsions organization and its applicative properties were investigated and discussed.

\section{Materials and methods}

\section{Materials}

Cetearyl Glucoside and Cetearyl alcohol mixture, used as emulsifier, as well as the Phenoxyethanol and Methylparaben and Ethylparaben and Propylparaben and Butylparaben, used as preservative, were provided by SEPPIC, France.

Isohexadecane and Caprylic capric glycerides were used as emollients. Their properties were already investigated [3] and the main results, describing their density, surface tension and interfacial tension values are resumed in Table I. 
Table I. INCI, trade name, the supplier and the codes of two selected emollients, near to of the density measurement results, surface tension, as well as interfacial tension values.

\begin{tabular}{ccccccc}
\hline INCI & Trade name & Supplier & Code & Density & $\begin{array}{c}\text { Surface tension } \\
(\mathrm{mN} / \mathrm{m})\end{array}$ & $\begin{array}{c}\text { Interfacial tension versus water } \\
(\mathrm{mN} / \mathrm{m})\end{array}$ \\
$\begin{array}{ccccc}\text { Isohexadecane } \\
\text { Isohexadecane }\end{array}$ & IMCD & IHD & 0.787 & $24.40 \pm 0.03$ & $43.61 \pm 2.72$ \\
\hline $\begin{array}{c}\text { Caprylic/Capric } \\
\text { Triglyceride }\end{array}$ & Myritol 318 & BASF & CCT & 0.948 & $28.95 \pm 0.04$ & $13.49 \pm 0.22$ \\
\hline
\end{tabular}

\section{Methods}

\section{Emollients contact angle measurement}

The test was performed using a portative goniometer PGX+ (ScanGaule, Gravigny, France) connected to the PGPlus software. It is equipped with a high-resolution camera to acquire images, with a specific lighting system associated with a mirror to visualize the liquid droplet deposited onto the surface. A syringe $(\varnothing=0.77 \mathrm{~mm})$ was used to depose the first droplet on the skin surface and its volume was increased by the addition of five successive drops to approximately $7 \mu \mathrm{L}$. A photograph was taken after each liquid addition and the advanced contact angle was determined on the identified triple point (intersection of the liquid, solid and vapour phases using the software). Advancing contact angle was measured at least in triplicate for each emollient.

\section{Emulsions formulation}

Emulsions were prepared as follows: first, the oil phase $\left(20 \%\right.$ of emollient) and $5 \%$ of emulsifier were heated up to $75^{\circ} \mathrm{C}$ under mechanical stirring $(400 \mathrm{rpm})$; then, the oily phase was added to the water phase previously heated at $75^{\circ} \mathrm{C}$. The mixture was then homogenized at 10,000 rpm for one minute using a T25 digital ultra-turrax (IKA, Freiburg, Germany) equipped with the dispersing head S25N-25F. Finally, the formulations were left cooling down to $30^{\circ} \mathrm{C}$ under mechanical stirring (400rpm) and then the preservative was added. Once prepared, the mixtures were split into three samples, stocked at $4^{\circ} \mathrm{C}, 40^{\circ} \mathrm{C}$ and ambient temperature, respectively, for stability monitoring.

\section{Optical microscopy}

The emulsions microstructure was observed without sample dilution by means of a photomicroscope (Leica DMLP microscope) equipped with a digital camera at a magnification of x200: first, under the bright field and secondly, under the polarized light (using cross-polarizers) in order to evidence the presence and characterize the liquid-crystal phases. Leica IM 1000 software was used to analyse the micrographs.

\section{Droplet size distribution}

The emulsion droplets size were measured by static light scattering (SLS) using a laser diffraction particle size analyser SALD7500 nano (Shimadzu Co., Ltd, Japan) equipped with a violet semiconductor laser $(405 \mathrm{~nm}$ ) and a reverse Fourier optical system (the beam converge before encountering the sample). The emulsions were diluted with deionized water to achieve the absorption parameter equal to 0.2. Once introduced into the batch cell $\left(7 \mathrm{~cm}^{3}\right)$, the emulsions were stirred during the measurement to assure homogenous dispersion. Data were analysed using software Wing SALD II and the droplets mean values for each emulsion were acquired.

\section{Rheological measurements}

A continuous flow ramp was performed using a controlled stress rheometer (HR1, TA instruments).

Emulsions analysis. Flow curves were obtained by recording shear stress and viscosity values at increasing shear rates ranging from 0.001 to $8000 \mathrm{~s}^{-1}$ (continuous ramp, logarithmic mode) for $300 \mathrm{~s}$. A cone-plate aluminium device was used, with a diameter of $40 \mathrm{~mm}$, a cone angle of $1^{\circ} 59^{\prime} 38^{\prime \prime}$ and a gap of $47 \mu \mathrm{m}$.

Emollients analysis. Flow properties were obtained by recording shear stress and viscosity values at increasing shear rates ranging from 0.1 to $50000 \mathrm{~s}^{-1}$ (continuous ramp, logarithmic mode) for $300 \mathrm{~s}$. For this test, an aluminium plane geometry (60 $\mathrm{mm}$ ) was used. 
All the measurements were carried out in duplicate at $25^{\circ} \mathrm{C}$. The solvent trap was used to prevent sample drying. Once loaded, the samples were left at rest for two minutes prior to any measurement. Samples were analysed once and then changed prior to further analysis.

\section{Wide-angle X-ray diffraction (WAXD)}

Samples were analysed in a reflection mode by X-ray diffraction (XRD) using a PANalytical Xpert Powder diffractometer (PANalytical B.V., Almelo, The Netherlands) with a $\mathrm{CoK}_{a}(\lambda=1.7902 \AA)$ monochromatic radiation source, and operating voltage and current maintained at $40 \mathrm{kV}$ and $40 \mathrm{~mA}$, respectively. A $15 \mathrm{~mm}$ mask was used. The detector was a linear PIXcel1D detector. Data was acquired by steps of $0.02^{\circ}$ for $2 \theta$ values ranging from 2 to $50^{\circ}$. The formulations were pressed under Capton foil, avoiding air bubbles.

From diffraction angle theta $(\theta)$ the interlayer spacing was calculated according to Bragg's law.

\section{Thermogravimetric analysis}

Thermogravimetric analysis (TGA) was performed on a Setsys apparatus (Setaram, Caluire-et-Cuire, France) with the Setsoft software. Around $35 \mathrm{mg}$ of emulsion were weighed and heated under the air atmosphere by the following procedure:

- $\quad$ Isotherm: $300 \mathrm{sec}$ at $25^{\circ} \mathrm{C}$;

- $\quad$ Ramp: $25^{\circ} \mathrm{C}$ to $130^{\circ} \mathrm{C}$ at $2^{\circ} \mathrm{C} / \mathrm{min}$;

- Isotherm: $120 \mathrm{sec}$ at $130^{\circ} \mathrm{C}$.

The weight loss of the sample is registered as a function of temperature (\% mass loss/total mass). The first derivative of the TGA curve (the DTG curve) was also plotted to visualise the water evaporation dynamics (\%/min).

\section{Texture analysis}

Texture analysis was performed using a TA.XT Plus (Stable Micro Systems, Cardiff, UK). The apparatus was equipped with a friction module A/FR (ASTM-D 1894-90) to perform the spreading test. The protocol was adapted from Gilbert [12] and it represents the spreading of $200 \mu \mathrm{L}$ of the cream between two surfaces, polypropylene plastic sheet and Helioplate ${ }^{\mathrm{TM}} \mathrm{HD} 2$ (Helioscreen, Marseille, France), over $120 \mathrm{~mm}$ distance and at a constant speed $(3 \mathrm{~mm} / \mathrm{sec})$. The force required to spread the sample is registered as a function of time.

The area under the curve $A+(\mathrm{g} \cdot \mathrm{sec})$, describing the difficulty to spread the product was then calculated. Also, the slope of the force curve was estimated, to interpret the evolution of the spreading of the product function of time. Finally, the affinity of the product with the polypropylene surface was evaluated through the shape of the force curve, namely through the calculation of the noise amplitude. Three repetitions were performed for each sample.

\section{Sensory analysis}

Two attributes corresponding to different phases of a cosmetic emulsions application were evaluated (Table II). A positive displacement pipette equipped with capillary pistons, Microman, was used to deliver an exact amount of the emulsion on the skin.

The recruited panel was composed of 10 volunteers aged from 22 to 36 years with Caucasian skin type. Two training sessions were organized for each attribute to acquire the definition, the evaluation procedure, the rating scale and the commercial references. Then, each product was evaluated twice.

Table II. Definitions and scales used to describe the selected attributes (compression force and difficulty of spreading) for the sensory analysis.

\begin{tabular}{cclc}
\hline Phases & Attributes & \multicolumn{1}{c}{ Definitions } & Scales \\
\hline Pick-up & Compression force & $\begin{array}{l}\text { Force required to fully compress product between } \\
\text { thumb and forefinger }\end{array}$ & 0 (soft) $\rightarrow 7$ (hard) \\
\hline Rub-out & Difficulty of spreading & Force required to move the product over the skin & 0 (soft) $\rightarrow 7$ (hard) \\
\hline
\end{tabular}




\section{Data analysis}

Results were presented as the mean value \pm standard deviation (SD).

XLSTAT software (Addinsoft, Paris, France) was used to perform the statistical analyses of the collected data. The ANOVA test (two-way analysis of variance) was applied to the results to spot the significant differences between the emulsions $(P<0.05)$. Mean intensities were compared using the Tukey multiple comparison tests to distinguish different groups of products.

\section{Results and discussion}

\section{Evidence of the presence of liquid crystals in the emulsions}

The first part of the present work focuses on the detailed characterization of the emulsions. It should be mentioned that in the previous study the quantity of the APG surfactant was higher than usual in order to induce an abundant presence of liquid crystals. Here, the main goal was to obtain systems at limited emulsifier level for a topical application but still keeping $\alpha$-gel organization. Therefore, Cetearyl alcohol/Cetearyl glucoside emulsifier was fixed at $5 \%$ near to $20 \%$ of emollient in emulsions containing: isohexadecane (EM_IHD) or caprylic/capric triglycerides (EM_CCT). The occurrence of liquid crystals structures was checked with several analyses as presented afterwards.

\section{Microscopy and static light scattering}

Firstly, the two distinct emollient containing emulsions show classical oil droplets dispersed in the continuous aqueous phase. As visible in Fig.1, the emulsion prepared with non-polar oil IHD owns larger droplets when compared to the one prepared with polar emollient CCT. This result is consistent with previous observations obtained with higher surfactant content, thus confirming that oil polarity governs the emulsion's microstructure [3]. Liquid crystals formation was confirmed through the microscopy under the polarized light observations. The "onion rings" observed for both emulsions undoubtedly pointed at the organization of the surfactant in lamellas $[13,14]$. As expected, these structures were formed due to the presence of alkyl polyglucoside and fatty alcohol mixed emulsifier, which is known for favouring the lamellar phase formation $[15,16]$.

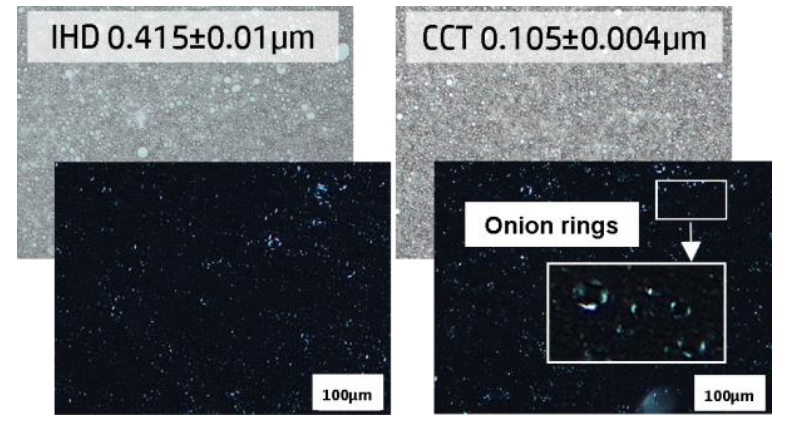

Figure 1. Bright field and polarized light micrographs of the emulsions containing isohexadecane as nonpolar oil and caprylic/capric triglycerides as polar emollient at $20 \%$ with the median droplet size values for each sample.

Next, a wide angle X-rays analysis was performed to access the molecular organization of the matrix and to interpret the extent of the surfactant - emollient interactions.

\section{Wide angle X-rays diffraction}

As explained earlier, the two main lamellar organizations are lamellar liquid crystals $\left(L_{\alpha}\right)$ and $\alpha$-gel $\left(L_{\beta}\right)$, respectively. In the $L_{\alpha}$ phase, the hydrocarbon chains are in a liquid-like state while in the $L_{\beta}$ phase, the hydrocarbon chains remain stiff, perpendicular to the plane of the lamellae, with the axes organized as a two-dimensional hexagonal lattice [5]. Both organizations may be efficiently observed by WAXD [17].

Fig. 2 depicts the WAXD patterns for both EM_IHD and EM_CCT emulsions. The most representative sharp peak at $0.412 \mathrm{~nm}$ corresponds to $\alpha$-gel as reported in the literature $[13,18]$. Meanwhile, the presence of the lamellar liquid crystals $\left(L_{\alpha}\right)$, with 
"fluid-like" characteristics, can also be evidenced at $0.46 \mathrm{~nm}[19,20]$, but only for EM_CCT. Thus, these results confirm that there are significant differences at the molecular level between the samples depending on the oil polarity. Although both emulsions contain $\alpha$-gel structures, the lamellar liquid phase is only present in case of "polar" emollients (containing heteroatoms).

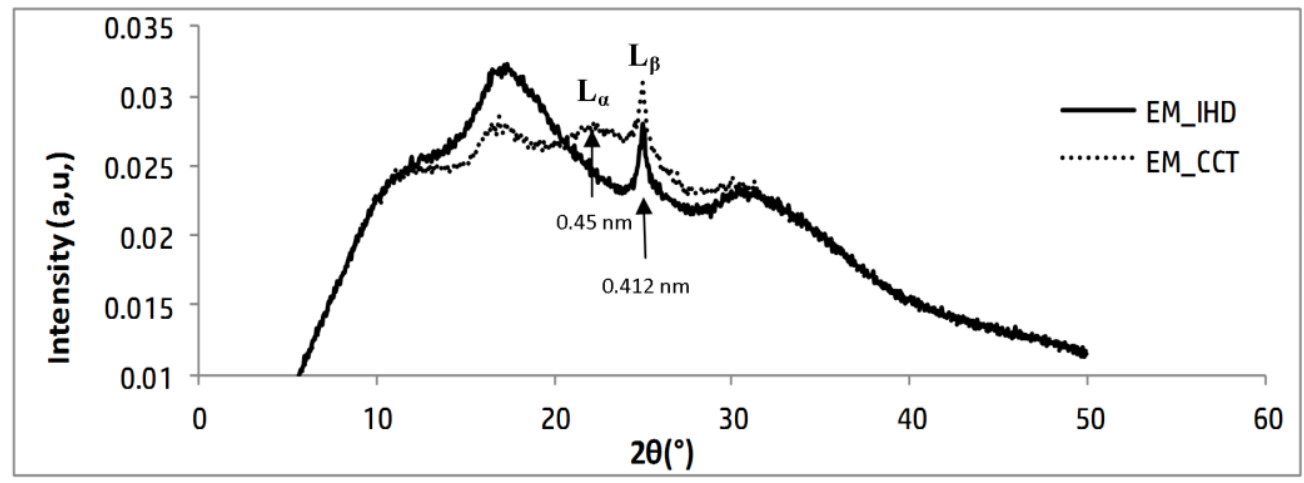

Figure 2. WAXD patterns of IHD and CCT emulsions. The intensity $(a, u$,$) is represented as a function of the 2 \theta^{\circ}$. The sharp peak at $0.412 \mathrm{~nm}$ corresponds to the $\alpha$-gel $\left(L_{\beta}\right)$ formation in both samples, while the diffuse halo at $0.45 \mathrm{~nm}$ present in EM_CCT sample is a sign of the lamellar liquid phase formation.

Such results are of primary importance to whom interested in understanding the liquid crystals occurrence in emulsions; thus, the following explanations, together with schematic representation for the corresponding liquid crystals structures, are proposed. IHD emollient being completely hydrophobic, mainly inserts between the alkyl part of the surfactant layer (Fig.3a), with no or fair disruption for the alkyl chains organization as illustrated in Fig.3b. On the contrary, for CCT sample, interactions with the surfactants polar head occur, in addition to the nonpolar interactions with the surfactant alkyl part, causing reorganization for the surfactant-emollient system. Thus the formation of lamellar liquid phase is induced as schematized on Fig.3c.

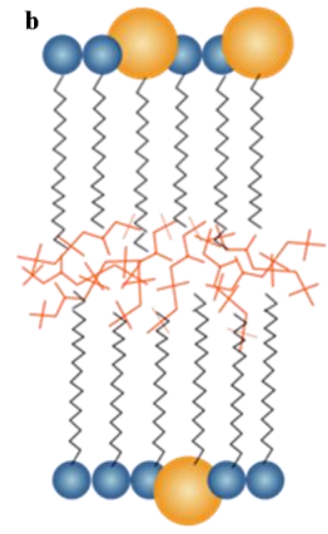

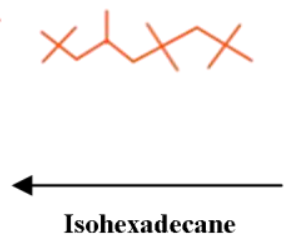

Isohexadecane

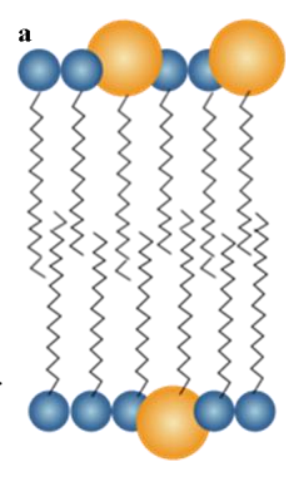

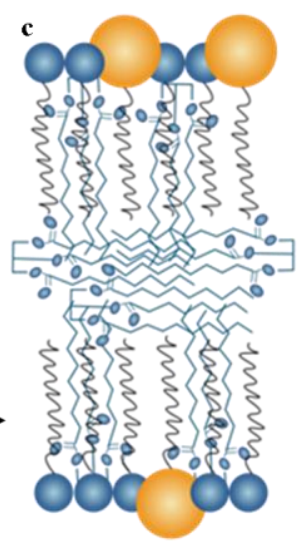

Figure 3. Schematic representation of the (a) initial $\alpha$-gel formed by the APG mixed emulsifier; (b) once isohexadecane is added to the system without disturbing stiff hydrocarbon chains; (c) when heteroatom-containing molecules of caprylic capric triglycerides are inserted between alkyl chains, making them more flexible and thus forming lamellar liquid phase.

To sum up, the above results confirmed the occurrence of surfactant lamellar liquid crystals for the emulsions containing polar emollient. The effect of the emollients chemical structure on the $\alpha$-gel thus remains unchanged when compared to previous results obtained with higher surfactant content. As expected, such structural differences do imply different microscopic and macroscopic properties for the corresponding emulsions as evidenced through rheological tests. A higher elastic modulus $\mathrm{G}^{\prime}$ for the $\alpha$-gel containing samples ( $G^{\prime} E M \_I H D=820 \pm 11 \mathrm{~Pa}$ ) versus those possessing complementary lamellar liquid crystals ( $\mathrm{G}^{\prime} \mathrm{EM} \_\mathrm{CCT}=556 \pm 8 \mathrm{~Pa}$ ) was reached.

Nevertheless, it is important reminding that water remains the main component for the studied emulsions. Although water plays a key role in the continuous phase properties, it may also be entrapped inside the surfactant-oil lamellar organization. 
Therefore, it is crucial to fully understand the water distribution within the emulsion matrix. The different types of water were investigated through thermogravimetric analysis experiments.

\section{TGA analysis}

Several examples in the literature evoke thermogravimetric technique as a good methodology to describe the types of water present in emulsified systems [21-23], all being based on the work by Junginger et al [24]. The authors described the thermal behaviour of an emulsion containing crystalline gel structures. Three distinct steps of water evaporation were specified in this work depending on the corresponding temperature range:

- Up to $56^{\circ} \mathrm{C}$ : bulk water evaporation; water mechanically entrapped in the cetostearyl alcohol gel-network,

- Between $56^{\circ} \mathrm{C}$ (melting of the cetostearyl alcohol monohydrate) and $72^{\circ} \mathrm{C}$ : evaporation of the semihydrate water from cetostearyl alcohol and of hydrophilic gel phase, associated with the "secondary" water,

- $\quad$ Above $72^{\circ} \mathrm{C}$ : evaporation of interlamellar fixed water after melting of hydrophilic gel phase.

In our case, unlike the Junginger example, the water evaporation occurred in a single step for both emulsions. Inspired by the literature examples based on the same surfactant [23,25], we have also estimated the water loss as a function of three temperature ranges of evaporation. The water evaporation percentages of two emulsions depending on the studied zone are presented in Table III. Water samples were analysed in the same conditions and lead to the similar water loss profiles as emulsions (Table III). It should be mentioned that the third stage of EM_IHD is also influenced by the beginning of the IHD evaporation.

Table III. Percentage of the water loss / total water amount over the specified temperature ranges. The data should be compared by column. Two different letters in each column indicate the statistically significant differences between the products.

\begin{tabular}{|c|c|c|c|c|c|c|}
\hline \multirow{3}{*}{$\begin{array}{l}\text { Sample } \\
\text { EM_IHD }\end{array}$} & \multicolumn{6}{|c|}{$\%$ (water loss/water amount) } \\
\hline & \multicolumn{2}{|c|}{$30^{\circ} \mathrm{C}-50^{\circ} \mathrm{C}$} & \multicolumn{2}{|c|}{$50^{\circ} \mathrm{C}-70^{\circ} \mathrm{C}$} & \multicolumn{2}{|c|}{$70^{\circ} \mathrm{C}-110^{\circ} \mathrm{C}$} \\
\hline & 8.8 & A & 26.3 & A & 75.6 & A \\
\hline EM_CCT & 6.7 & B & 25.8 & A & 61.8 & B \\
\hline Water & 5.1 & B & 16.6 & B & 76.1 & A \\
\hline
\end{tabular}

It is interesting to notice that the pure water evaporation was less pronounced during the two first ranges compared to emulsions evaporation. As profile was similar for each sample, the slopes of the TG curves were also calculated between $30^{\circ} \mathrm{C}$ and $100^{\circ} \mathrm{C}$ to estimate the evaporation speed over the analysed temperature ramp.

The IHD sample shows higher evaporation speed, with the slope value equal to $-1.231 \pm 0.066$. The result is closer to the pure water evaporation $-1.237 \pm 0.055$, when compared to the CCT sample that possesses an evaporation rate equal to $-1.141 \pm$ 0.015. If transposing these results to the characteristics of liquid crystals in the emulsions (see wide angle X-Rays diffraction data), the lower water release rate from CCT containing samples may be explained by the presence of lamellar liquid crystals present in this matrix. This result and interpretations are consistent with the specific organization of such liquid crystals that, therefore, appear efficient for keeping the water entrapped when compared to the other structures.

This observation can be confirmed by the rheological temperature sweep test (Fig.4). The slope value of the water evaporation also depends on the destruction of the system due to thermal effect. The "melting" of the pure $\alpha$-gel intervenes in "one step" at $51^{\circ} \mathrm{C}(\tan \delta=1)$, while for the lamellar liquid crystals the temperature of melting is higher, at $64^{\circ} \mathrm{C}$. This can be explained by both the interactions between $L_{\beta}$ and water molecules and its higher resistance due to its flexibility. It is obvious that the presence of heteroatoms in the surfactant-CCT structure present in the $L_{\beta}$ phase induces polar intermolecular interaction, these last being favourable for water retention. On the contrary, such interactions do not exist in the case of IHD-surfactant, so consequently, this last system does not retain water molecules that much. Otherwise, as evidenced earlier in this paper, the relative disorganization of the surfactant bilayers when associated with CCT makes it more flexible when compared to the IHD surfactant mixture, and therefore more resistant to temperature thus slowing down the water release. 


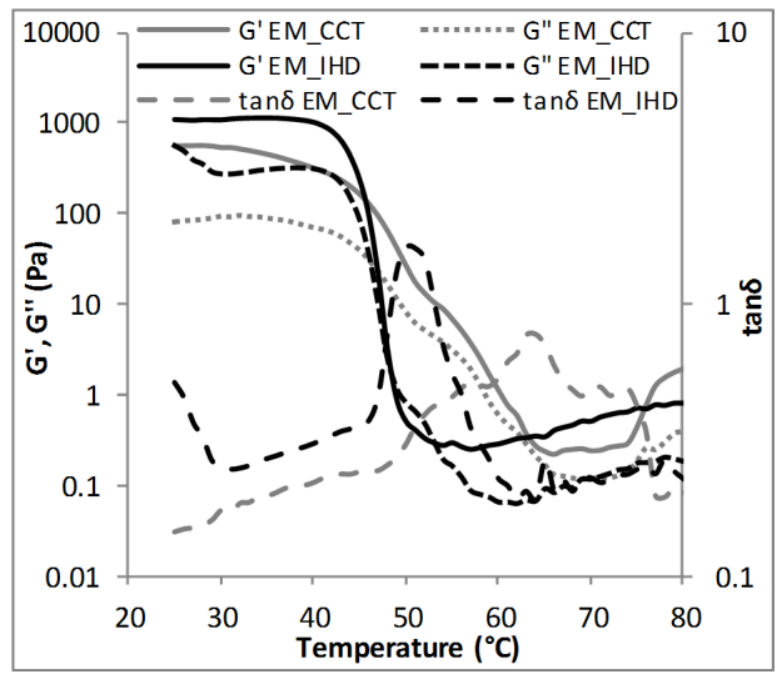

Figure 4. Temperature sweep test results for EM_IHD (black) and EM_CCT (grey). EM_IHD shows one-step destruction, with tan $\delta$ maximal value at $51^{\circ} \mathrm{C}$. The destruction of the EM_CCT is more progressive with maximal tan $\delta$ value at $64^{\circ} \mathrm{C}$.

Based on the literature $[2,24,26,27]$ and on the results previously described herein, a schematic representation of the two formulated emulsions can be proposed. On the one hand, the emulsion containing the nonpolar emollient is composed only of $\alpha$-gel (Fig.5a). On the other hand, if considering polar emollient, the lamellar liquid crystalline phase $\left(L_{\alpha}\right)$ is formed around the droplet near to the $\alpha$-gel, this last being still present in the emulsion (Fig.5b). Such a schematic view of the effect of emollient properties onto the emulsion's structure is consistent with the whole observations exposed above: the droplets size and shape as observed by microscopic techniques, liquid crystals formation as observed by polarized optical microscopy and XRD experiments, mechanical characteristics determined by oscillatory rheology and, finally, results issued from TGA measurements.
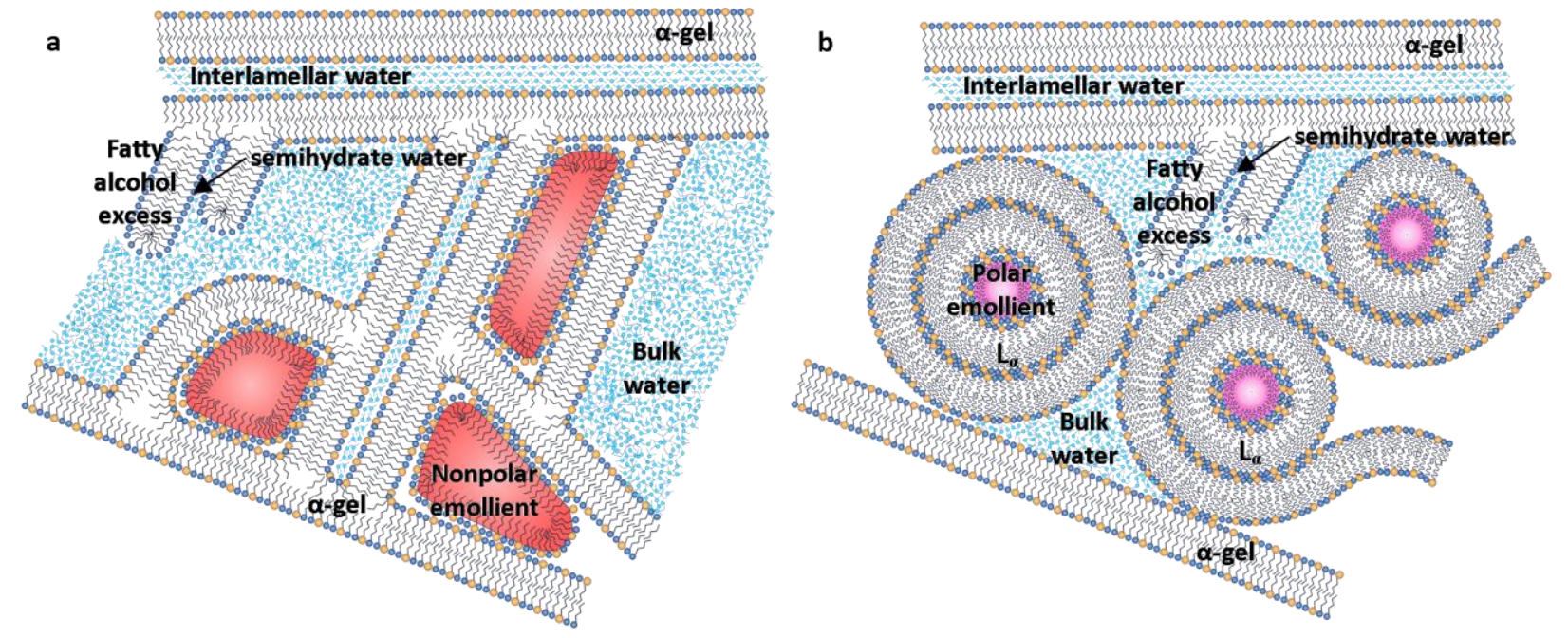

Figure 5. Schematic representation of the emulsion containing (a) nonpolar emollient. The oil droplets and the bulk water are entrapped by the $\alpha$-gel. For the (b) polar emollient, the droplets are complementarily surrounded by the lamellar liquid crystals $\left(L_{\alpha}\right)$. In both cases, the semihydrate water is retained by the fatty alcohol molecules, while the interlamellar water is placed between the $\alpha$-gel layers.

Once the emulsions substantially described, the second part of the project consisted in the sensory and instrumental analysis of their applicative properties. Compression force and difficulty of spreading were the most discriminative textural properties and correspond to two different application steps: pick up and rub-out. 


\section{Applicative properties: compression}

The results of the compression force sensory test are presented in Fig.6. The compression force is the evaluation of the products firmness during the pick-up phase.

The sensory panel felt the difference between the two products. At this stage, one can question whether the significant difference in perception is due to the emollient or to the specific structures created by the surfactant - emollient interaction. Thus, a complementary instrumental analysis was envisaged in order to answer this question.

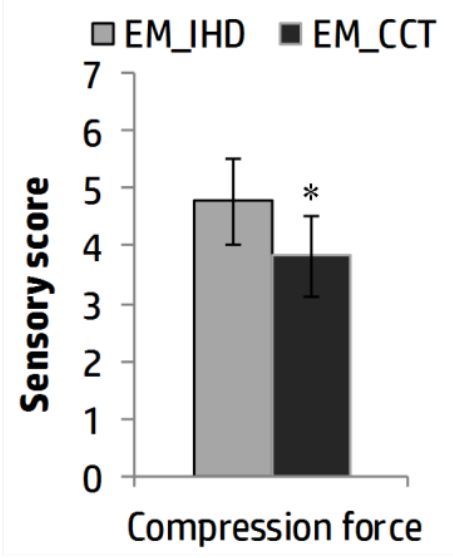

Figure 6. Sensory scores of EM_IHD and EM_CCT as a function of the compression force.

Several papers describe correlations between the sensory perception and the instrumental analysis for cosmetic products on the basis of rheology and texture analysis [28-31]. For the "compression force" sensory attribute, Gilbert et al. [28] described a good correlation $\left(R^{2}=0.961\right)$ with the test of compression with a texture analysis. Or, according to Barnes [32], the various physical operations with emulsions can be also expressed by some typical shear rate ranges. As an example, the shear rate corresponding to the compression force attribute can be placed around $10^{2} \mathrm{~s}^{-1}$. Thus, the apparent viscosity of both emulsions and the pure IHD and CCT emollients at this share rate was measured during a flow test experiment. As visible in Table IV, the dynamic viscosities of the emulsions are much higher than those of pure emollients and do not follow the same order. This illustrates the major role of the emulsion's structure and organization when compared to the components taken alone.

Table IV. Viscosity values of EM_IHD and EM_CCT emulsions and corresponding pure emollients at the $10^{2} \mathrm{~s}^{-1}$ shear rate.

\begin{tabular}{llll}
\hline Emulsions & Viscosity (Pa.s) & Emollients & Viscosity (Pa.s) \\
\hline EM_IHD & $1.252 \pm 1.82 \mathrm{E}-02$ & IHD & $0.003 \pm 4.21 \mathrm{E}-05$ \\
EM_CCT & $0.504 \pm 2.87 \mathrm{E}-03$ & CCT & $0.017 \pm 4.58 \mathrm{E}-04$ \\
\hline
\end{tabular}

The compression parameter appears mainly governed by the molecular organization of the emulsion. The viscosity of the emollient alone does not affect the pick-up parameter. This is due to the fact that the droplets are not disrupted during this test. Instead, the indirect impact on the organization of the liquid crystals and, as consequence, on the compression values is observed. Compression force appears strongly related to the rigidity of the surfactant bi- and multi-layers organization, which depends on the emollient molecular peculiarities.

\section{Applicative properties: spreading profile}

The sensory perception of the "difficulty of spreading" attribute is presented in Fig.7. This attribute does not follow the same ranking as compression attribute exposed above. EM_CCT appears more difficult to spread on the skin than EM_IHD. In this case, in order to understand which parameters are involved in this texture perception, the spreading property was evaluated through an instrumental test inspired by the literature. 


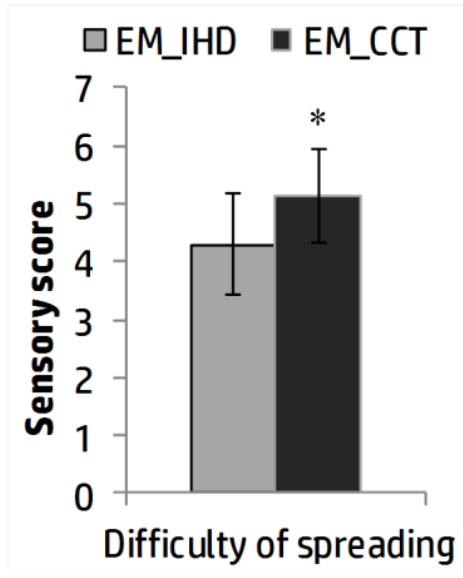

Figure 7. Sensory scores of EM_IHD and EM_CCT as a function of the difficulty of spreading.

Some specific tests, developed to mimic the sensory analysis, were described in the works by Laura Gilbert [12,33], where different correlations between physical and sensory tests were established. In the present work, our interest was focused on the spreading test. Both Savary et al. [10] and Gilbert et al. [12] proposed optimal conditions for measuring the spreading properties of emulsions using either a PMMA plate and a polypropylene sheet as surfaces for spreading tests. The same conditions were used in the present study to elucidate whether the spreading properties of emulsions are only governed by the oil phase or by the oil/surfactant interaction. Measurements were performed on both the pure emollients and the emulsions.

In order to transpose the emollients behaviour from the instrumental towards the sensory perception, emollients were characterized according to their contact angle formed on the human skin (Fig.8). The IHD, as nonpolar oil, showed higher spreading that CCT as illustrated by spontaneous larger contact surface on the skin and, as a consequence, a smaller contact angle when compared to CCT.

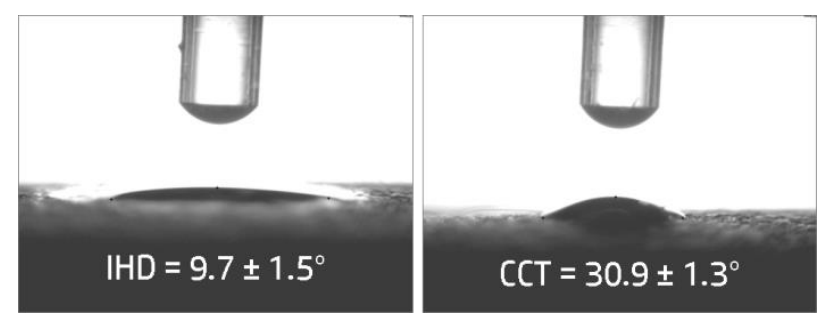

Figure 8. Droplet shape of IHD and CCT emollients on the human skin and mean values of the emollients contact angle versus skin $\left({ }^{\circ}\right)$.

Results for the contact angle can be linked to the conditions of the instrumental spreading test. Because the surface energy of the polypropylene and PMMA is equal to $30.1 \mathrm{mN} / \mathrm{m}$ and $41.1 \mathrm{mN} / \mathrm{m}$ respectively [34], these two materials can be considered as fairly comparable to the skin surface in terms of surface energy, the skin owning a surface energy around $38.7 \mathrm{mN} / \mathrm{m}$ [35].

Then the friction test was performed in two steps. First, the spreading profile was drafted for the pure emollients and then, for the corresponding emulsions. Once the experiments performed, several data were calculated on the basis of the force evolution monitored over time (Fig.9). The following parameters were determined:

- $\quad$ A+ (g.sec), the positive area under the force curve;

- $\quad$ Slope value on the force curve;

- $\quad$ The amplitude of the force variation during the test (g).

Fig.9 illustrates that the emollients force versus time curves present a typical, standard profile. The areas under the curves were higher when compared to the baseline, meaning that the presence of emollients induces friction forces more important than between both surfaces without product. The positive area under the force curve $(2326 \pm 49 \mathrm{~g}$.sec for IHD and $2751 \pm 62 \mathrm{~g}$.sec for CCT) showed the easier spreading of the nonpolar emollient versus the polar one. Interestingly, the affinity of emollient with the surface material was estimated through the noise values as illustrated by Fig.9c: the larger the noise amplitude, the more the sample withstands the surface material. Here, the surface used for the textural characterization was non-polar (polypropylene) 
and, as expected, the pure raw materials clearly developed specific interactions with this support. This could be estimated by the "noise amplitude parameter": IHD one was 9g while CCT one was 30g. These observations were consistent with the contact angle measurements, the nonpolar oil (IHD) owning higher affinity with the polypropylene sheet when compared to the polar CCT one.

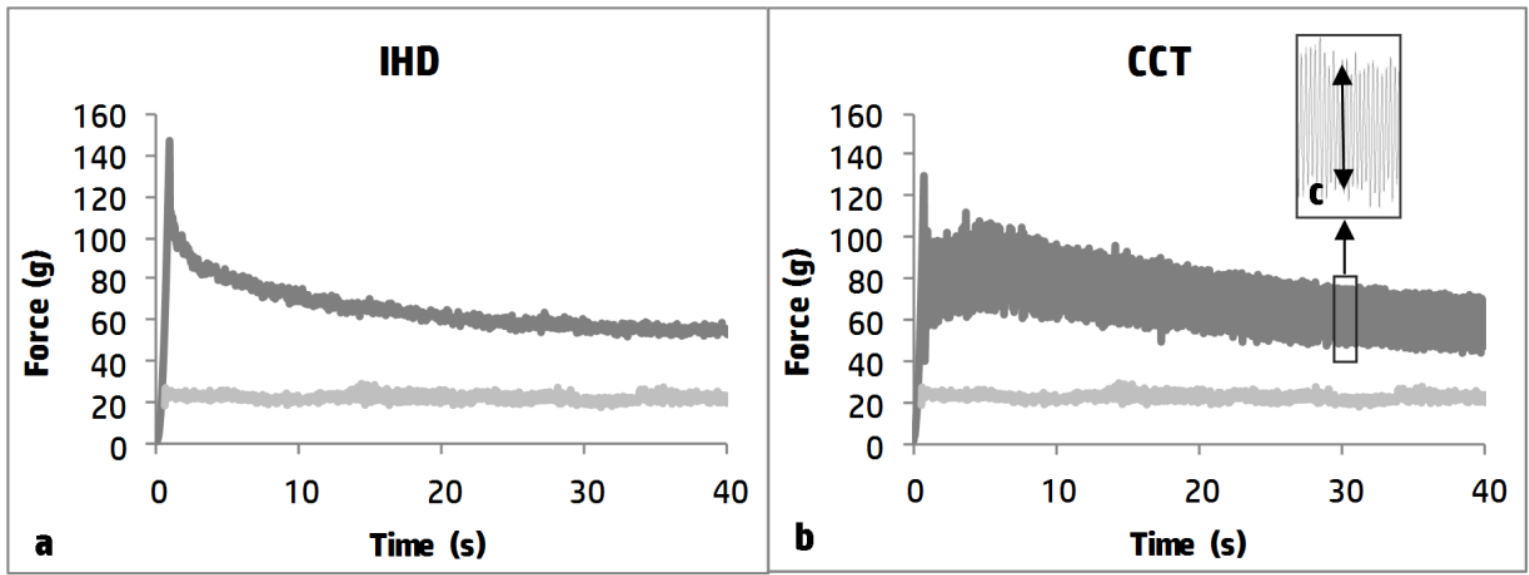

Figure 9. Spreading profile of a) pure IHD emollient and b) CCT emollient with its c) noise amplitude example, with the baseline plotted in light grey.

The force curve was analysed over the studied $120 \mathrm{~mm}$ of the spreading distance. All the emollients gave a negative force slope value, with -0.69 for IHD and -0.61 for the CCT, respectively. This suggests that the force decreases during the test, thus the spread becomes easier once the quantity of the product between the two surfaces decreases and the values tend to reach a constant curve value. One can conclude that these results are not only influenced by the emollient viscosity, but also by the emollient/solid support affinity.

Considering the emulsions, the evolution is far different from the one observed for the pure oils. As an illustration for IHD and CCT based emulsions, Fig.10 shows that the emulsion first favours the spreading of the sled, the force values being lower than the baseline. Next, once the thickness of the cream becomes thin enough but still visible, the spreading becomes more difficult (after 20 seconds of spreading).
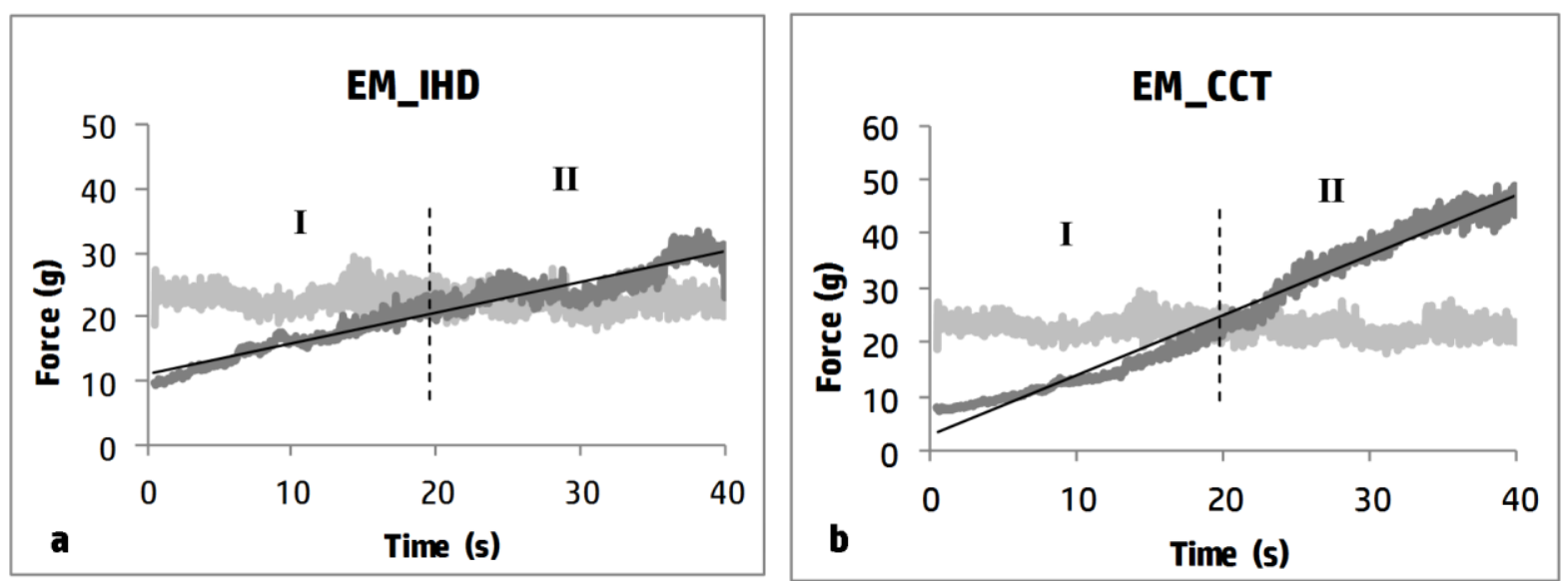

Figure 10. Spreading profile of a) EM_IHD and b) EM_CCT emollient with the baseline plotted in light grey. The slope value of the force curve was calculated over the whole distance. Also, complementary slope I and slope II were calculated and correspond to the spreading between 0 and 20 seconds (lower to the baseline) and between 20 and 40 seconds (superior to the baseline).

The slope values obtained for the studied emulsions are presented in Table $\mathrm{V}$. The differences between the slopes of the products appear statistically significant. 
Table V. Slope values of the force curve obtained during the total test time, slope I corresponds to the spreading between 0 and 20 seconds (lower to the baseline) and between 20 and 40 seconds (superior to the baseline).

\begin{tabular}{ccc}
\hline & EM_IHD & EM_CCT \\
\hline Slope & $0.506 \pm 0.06$ & $1.095 \pm 0.036$ \\
Slope I & $0.549 \pm 0.107$ & $0.816 \pm 0.041$ \\
Slope II & $0.507 \pm 0.053$ & $1.027 \pm 0.139$ \\
\hline
\end{tabular}

One can notice that slope I and II are also quite different depending on the studied emulsion. The slope I corresponds to the first step of spreading when the droplets are rolling one on another without being disrupted. The slope I value of the EM_CCT is higher than the EM_IHD, arriving at the same baseline. Consequently, lamellar liquid crystals are easier to spread at the very beginning of the test, contrary to the $\alpha$-gel.

The second step of the spreading test is shown by the slope II. It represents the interaction between IHD or CCT emollient with the support once the droplets are disrupted. Logically, the spreading of the CCT polar emollient is more difficult on the non polar surface, making the EM_CCT slope II superior to the EM_IHD.

The information obtained from this test are consistent with the sensory analysis scores and follow the conclusions based on the oils contact angle results. When the contact angle increases (which means affinity with nonpolar surface decreases) the spreading becomes more difficult and requires the application of a higher mechanical force. So, as illustrated for the attribute "difficulty of spreading", one may consider that this attribute evaluated during application actually depends on both oil phase/matrix interactions (first stage) and oil phase individual properties once the matrix is disrupted (second stage).

\section{Conclusion}

This study was based on cosmetic emulsions containing liquid crystals of lamellar type. Liquid crystals structures were obtained using a mixed emulsifier Cetearyl alcohol/ Cetearyl glucoside. Two emollients were selected as oil phases. Isohexadecane (IHD) was chosen as representative nonpolar oil, while Caprylic capric triglycerides (CCT), a widely used cosmetic emollient, was selected as the polar one. The difference of polarity was mainly due to the absence (IHD) or the presence (CCT) of heteroatom. Emulsions were formulated with $20 \%(\mathrm{w} / \mathrm{w})$ of oil and $5 \%(\mathrm{w} / \mathrm{w})$ of the emulsifier, thus making them suitable for topical application.

Due to the chemical differences between the emollients, two different molecular organisations were obtained for the emulsions. The formation of $\alpha$-gel was assured in both the IHD and CCT containing emulsions (EM_IHD and CCT_EM, respectively). In addition to that, only EM_CCT emulsion showed the presence of the lamellar liquid crystals near to $\alpha$-gel. Such distinct molecular organizations markedly impact both the microscopic and macroscopic properties of the systems. EM_CCT formed oil droplets of a smaller size when compared to EM_IHD. Also, the polar oil containing emulsion showed a lesser dynamic viscosity, but a better thermal resistance than the nonpolar one. Finally, the whole results allowed demonstrating that the matrix type impacted the water organization and, consequently, the rate of the water release. This result was explained by higher water retention within the disorganized and more hydrophilic lamellar structures evidenced for emulsions containing polar emollient.

This work brings new approaches to the interpretation of surfactant/oil interactions, by elucidating the role of the molecular organization in the macroscopic and sensory properties of cosmetic emulsions. The proposed interpretations are always supported by a combination of analytical techniques and, therefore, are largely reliable.

For the compression force attribute, the sensory perception was coupled to the dynamic viscosity analysis. It was shown that emollients physical properties do not directly affect the pick-up perception of the emulsions. Meanwhile, the oil phase affects this attribute indirectly, through building specific structures together with the surfactant, like lamellar liquid crystal phase and $\alpha$ gel.

To describe the difficulty of spreading attribute, sensory and texture analysis, as well as emollients contact angle measurements were used. As for the previous parameter, the first step of the spreading test mainly depends on the emulsions molecular organization. Furthermore, the most noticeable perception occurs during the second step, once reached the disruption of the 
emulsion's structure. Then, as the emollient enters in the direct contact with the skin, the spreading perception and evaluation become fully dependent on the physicochemical affinity of the pure emollient with the skin.

The importance of this work lies in the full control of the emulsions composition and structure. Due to a specific multiscale approach and to a thoughtful choice of raw materials we managed to form the different emulsions with a full understanding and control of their molecular organization. On this basis, it was possible not only to describe, but also to interpret and then to explain both the macroscopic and the applicative properties of the emulsions.

\section{Conflicts of interest}

There are no conflicts to declare.

\section{Acknowledgements}

This work has been carried out in the context of the ALGRAAL, selected as Project of Excellence by the General Directorate for Competitiveness Industry and Services (DGCIS) in the 16th Appeal FUI (Fonds Unique Interministériel). The authors gratefully acknowledge the financial support of the FUI and the Région Normandie. 


\section{Bibliography}

[1] Knowlton J, Pearce S. Handbook of Cosmetic Science and Technology. Elsevier Advanced Technology, (1993).

[2] Tadros TF. Phase behaviour of surfactant systems. Applied Surfactants. Wiley-VCH Verlag GmbH \& Co. KGaA, pp.53-72 (2005).

[3] Terescenco D, Picard C, Clemenceau F, Grisel M, Savary G. Influence of the emollient structure on the properties of cosmetic emulsion containing lamellar liquid crystals. Colloids Surf. Physicochem. Eng. Asp., 536, 10-9 (2018).

[4] Tardieu A, Luzzati V, Reman FC. Structure and polymorphism of the hydrocarbon chains of lipids: A study of lecithin-water phases. J. Mol. Biol., 75, 711-33 (1973).

[5] Neto AMF, Salinas SRA. The physics of lyotropic liquid crystals : phase transitions and structural properties. Oxford University Press, (2005).

[6] Wenninger JA, Canterbery RC, McEwen GN, Cosmetic T and FA. International Cosmetic Ingredient Dictionary and Handbook. Cosmetic, Toiletry, and Fragrance Association, (2000).

[7] Chorilli M, Prestes PS, Rigon RB, Leonardi GR, Chiavacci LA, Sarmento VHV, Oliveira AG, Scarpa MV. Structural characterization and in vivo evaluation of retinyl palmitate in non-ionic lamellar liquid crystalline system. Colloids Surf. $B$ Biointerfaces, 85, 182-8 (2011).

[8] Lodén M. Role of Topical Emollients and Moisturizers in the Treatment of Dry Skin Barrier Disorders. Am. J. Clin. Dermatol., 4, 771-88 (2003).

[9] Stojiljković D, Arsić I, Tasic M, Jovanović Z, Tadic V, Đorđević S. Investigation of the effects of different emollients on the structure and skin moisturizing potential of the cosmetic creams. Acta Fac. Medicae Naissensis, 30, (2013).

[10] Savary G, Grisel M, Picard C. Impact of emollients on the spreading properties of cosmetic products: A combined sensory and instrumental characterization. Colloids Surf. B Biointerfaces, 102, 371-8 (2013).

[11] Zocchi G. Skin Fel Agents. Handbook of Cosmetic Science and Technology Second Edition. 3rd ed. (Barel André O , Paye Marc, Maibach Howard I ed.), CRC Press, pp.357-70 (2005).

[12] Gilbert L. Caractérisation physico-chimique et sensorielle d'ingrédients cosmétiques: une approche méthodologique. Université du Havre (2012).

[13] Fairhurst CE, Fuller S, Gray J, Holmes MC, Tiddy GJT, Demus D, Goodby J, Gray GW, Spiess H-W, Vill V. Lyotropic surfactant liquid crystals. Handbook of Liquid Crystals Set. Wiley-VCH Verlag GmbH, pp.341-92 (1998).

[14] Müller-Goymann CC. Liquid crystals in drug delivery. Encyclopedia of Pharmaceutical Technology: Volume 20 Supplement 3. (Swarbrick James, Boylan James C ed.), CRC Press, pp.109-49 (2000).

[15] Savic S, Tamburic S, Jancic B, Milic J, Vuleta G. The impact of urea on the colloidal structure of alkylpolyglucoside-based emulsions: Physicochemical and in vitro/in vivo characterization. Colloids in Cosmetics and Personal Care. (Tadros Tharwat F ed.), Wiley-VCH Verlag GmbH \& Co. KGaA, pp.259-274 (2008).

[16] Savić S, Savić M, Tamburić S, Vuleta G, Vesić S, Müller-Goymann CC. An alkylpolyglucoside surfactant as a prospective pharmaceutical excipient for topical formulations: The influence of oil polarity on the colloidal structure and hydrocortisone in vitro/in vivo permeation. Eur. J. Pharm. Sci., 30, 441-50 (2007).

[17] Eccleston GM, Behan-Martin MK, Jones GR, Towns-Andrews E. Synchrotron X-ray investigations into the lamellar gel phase formed in pharmaceutical creams prepared with cetrimide and fatty alcohols. Int. J. Pharm., 203, 127-39 (2000).

[18] Kalnin D, Garnaud G, Amenitsch H, Ollivon M. Monitoring fat crystallization in aerated food emulsions by combined DSC and time-resolved synchrotron X-ray diffraction. Food Res. Int., 35, 927-34 (2002).

[19] Rand RP, Luzzati V. X-Ray diffraction study in water of lipids extracted from human erythrocytes. Biophys. J., 8, 125-37 (1968).

[20] Larsson K. Crystal and liquid crystal structures of lipids, New York (1976).

[21] Prestes PS, Soares FASM, Oliveira AM, Arêas EPG, Gioielli LA, Kaneko TM, Guimarães KL, Zanin MHA, Velasco MVR, Baby AR. Rheological measurements and thermal characterization of lamellar gel phase emulsions developed with cetearyl alcohol/nonionic ethoxylated surfactants. J. Dispers. Sci. Technol., 33, 1621-8 (2012). 
[22] Nesseem DI. Formulation and evaluation of itraconazole via liquid crystal for topical delivery system. J. Pharm. Biomed. Anal., 26, 387-99 (2001).

[23] Savic S, Vuleta G, Daniels R, Müller-Goymann CC. Colloidal microstructure of binary systems and model creams stabilized with an alkylpolyglucoside non-ionic emulsifier. Colloid Polym. Sci., 283, 439-51 (2004).

[24] Junginger $\mathrm{H}$, Akkermans AAMD, Heering W. The ratio of interlamellarly fixed water to bulk water in O in W creams. J. Soc. Cosmet. Chem., 35, 45-57 (1984).

[25] Savić SD, Savić MM, Vesić SA, Vuleta GM, Müller-Goymann CC. Vehicles based on a sugar surfactant: Colloidal structure and its impact on in vitro/in vivo hydrocortisone permeation. Int. J. Pharm., 320, 86-95 (2006).

[26] Junginger HE. Ointments and creams as colloidal drug delivery systems. Colloidal drug delivery systems. Kreuter, J. ed., Marcel Dekker, New York, pp. 1-30 (1994).

[27] Junginger HE. Pharmaceutical emulsions and creams. Emulsions - A Fundamental and Practical Approach. Springer, Dordrecht, pp.189-205 (1992).

[28] Gilbert L, Savary G, Grisel M, Picard C. Predicting sensory texture properties of cosmetic emulsions by physical measurements. Chemom. Intell. Lab. Syst., 124, 21-31 (2013).

[29] Dubuisson P. Influence de la phase grasse et des polymères naturels sur les paramètres physicochimiques en lien avec la perception tactile de l'émulsion. Normandie université (2017).

[30] Estanqueiro M, Amaral MH, Sousa Lobo JM. Comparison between sensory and instrumental characterization of topical formulations: impact of thickening agents. Int. J. Cosmet. Sci., 38, 389-98 (2016).

[31] Moravkova T, Filip P. Relation between sensory analysis and rheology of body lotions. Int. J. Cosmet. Sci., 38, 558-66 (2016).

[32] Barnes HA. Chapter 18 The rheology of emulsions. Interface Science and Technology. Vol. 4, pp.721-59 (2004).

[33] Gilbert L, Picard C, Savary G, Grisel M. Rheological and textural characterization of cosmetic emulsions containing natural and synthetic polymers: relationships between both data. Colloids Surf. Physicochem. Eng. Asp., 421, 150-63 (2013).

[34] Gooch JW. Surface energy. Encyclopedic Dictionary of Polymers. (Gooch Jan W ed.), Springer New York, pp.716-7 (2011).

[35] Agache P. Presentation of the skin surface ecosystem. Measuring the skin / Aude Agache / Springer. pp.21-31 (2004). 